\title{
MODELLING IN SUPPORT OF DECISION-MAKING FOR SOUTH AFRICAN EXTENSIVE BEEF FARMERS
}

\author{
D. H. MEYER \\ Department of Statistics \\ Massey University Albany \\ Auckland, New Zealand
}

\begin{abstract}
In this study it is shown that it is possible to build a decision support system for the use of South African extensive beef farmers.

Initially models for the key variables which affect extensive beef farmers are developed. These key variables include rainfall, beef, veal and weaner prices and the condition of the veld. This last key variable is monitored using the voluntary lick intake of the cattle and is modelled in terms of rainfall and stocking intensity. Particular attention is paid to the interrelationships between the key variables and to the distribution of modelling errors.
\end{abstract}

The next stage of the study concerns the use of these models as a decisionsupport tool for extensive beef farmers. It is shown that Monte Carlo simulations and dynamic programming analyses can use these models to suggest how gross margins can be increased. At the same time these methods can be used to monitor the effect of management decisions on mean lick intake and, hence, the effect of these decisions on the condition of the veld. In particular the decisions of "what stocking intensity", "what cattle system", "when to sell" and "when to make a change" are addressed.

\section{GLOSSARY OF AGRICULTURAL TERMS}

Extensive beef farmer: Rancher who does not usually supplement natural grazing except with a lick.

Lick: A voluntary dietary supplement which is intended to make up for minerals and proteins which are deficient in the natural grazing. 
Heifer: Young female.

Tollie: Young male.

Weaner: A calf which has already been weaned.

LSU: Large stock unit - a calf counts as half a LSU.

Stocking Intensity: Herd size in relation to available grazing

Cattle System: Marketing Strategy (Tollie, Weaner or Calf System).

Tollie System: Geared to sell tollies (at an abattoir).

Weaner System: Geared to sell weaners (to a feedlot).

Calf System: Geared to sell calves (at an abattoir).

Herd Management System: incorporates strategies for veld management, supplementary feeding and breeding: excludes the marketing strategy referred to above as the "cattle system".

\section{INTRODUCTION}

Extensive beef farmers form a vulnerable sector in any oconomy. They have little if any bargaining power in the market, their product cannot be stored indefinitely and their costs and ability to produce are affected to a large extent by the vagaries of nature. In the United States of America extensive beef farmers use the American futures market to hedge their market prices, thereby reducing their overall risk to a more acceptable level. eg. Ikerd and Anderson [10]. In South Africa the Meat Board tries to reduce the risk of beef farmers using a system of floor prices. In this paper it is suggested that good statistical models may provide an alternative, or additional, solution to this problem. An example of such a decision support system is developed with the purpose of showing the extensive beef farmer the long-term implications of his decisions.

As stated by Hawryszkiewycz [9], decision support systems (DSS's) are usually based upon the output from a computer-based model which is continually refined in terms of its inputs. Thus, DSS's are a cheap form of experimentation. Keen and Morton [11] claim that DSS's are an attempt to match computer technology to the reality facing the decision-maker. These systems are only appropriate when management judgement is essential and, secondly, there is sufficient structure in the system to allow the use of a computer and other analytical aids. These 
systems improve management effectiveness by providing a supportive tool which can extend the range and capability of the manager's decision processes.

In this study we have developed such a tool for the use of South Africa's extensive beef farmers. However, we have ignored the problems of implementation. Implementation is the area in which many a DSS has faltered. The objective has been to merely show that it is possible to develop a DSS for extensive beef farmers. The job of building and implementing a final system has been left to others.

\section{SOURCES OF VARIABILITY}

There are three key variables which affect the decisions made by extensive beef farmers. Rainfall is certainly one of these variables. Drought brings to mind a spectre of starving cattle. However, the variability associated with the beef price cycle may be even more important to the extensive beef farmer. The third key variable is the condition of the veld.

Beef price cycles, with cycle lengths differing from one country to the next, are a universal phenomenon according to Breimyer [1]. These cycles are, in a sense, caused by the beef farmers themselves. Farmers tend to have a farm-view rather than an industry view. When prices start to rise farmers build up their herds by keeping more heifers (young cows), thus reducing the supply to the market and forcing prices higher. Their objective is to increase the number of new calves born, thus allowing them to increase future supply and, hence, future profits. However, any extensive farming ranch is limited in terms of the number of cattle it can support. Overgrazing is not encouraged in the industry. eg. Gammon [7], Richardson [20], Denny [3]. Consequently there soon comes a time when farmers start selling under pressure of the veld. This results in an over-supply and a rapid decline in prices. Williams and Stout [24] have much more to say about beef price cycles and their effect on the extensive beef farmer. Meadows [15] has explained how the supply cycles for beef and other agricultural products can be modelled in lorms of marketing lags, gestation lags and expected prices. 
As mentioned above, herd size has a major influence on the third kay variable, the condition of the veld. Of course the level of rainfall also has a major offoct on veld condition. There have been many attempts to measure the condition of the veld and hence to determine when the pressure on the veld should be reduced. eg. Westfall, van Rooyen and Theron [23]. But, as yet a suitable measure which incorporates both the palatability and quantity of grass available has yet to be produced. In this study it is suggested that the voluntary lick intake of the cattle should be used as the measure of veld condition. In other words, it is suggested that we should rely on the cattle themselves to tell us what they think of the veld condition.

Therefore in this study rainfall, beef price and lick intake (veld condition) are viewed as the most important variables which affect the decision-making of a South African extensive beef farmer. Veal and weaner prices, and mass gain for the different categories of animal, must also be incorporated in any analysis. However, other sources of risk, such as disease and death by natural causes or lightning strike, are ignored in an attempt to simplify what is already a complicated system.

\section{MODELS}

The development of all the models used in this study and their error distributions are described by Meyer[16]. Since a long-term view is required, models which portray the long-term behaviour of rainfall and the beef price are derived. Cyclical models are used for this purpose. The models were developed using data for cattle sold only at the Witwatersrand Auctions. All attempts to find a correlation between rainfall and beef prices failed as explained by Meyer [17]. As a result these two variables have been modelled independently of each other.

\section{The Rainfall Model}

The rainfall model developed here is based on the same forty years of raw data used by Dyer [5] resulting in a rainfall model very similar to his. However, the time series used consists of a weighted average of monthly rainfalls for the various cattle production regions, with weights obtained from the number of cattle supplied 
by each production region to the Witwatersrand auctions. This weighted average rainfall time series appears in Figure 1 for the twenty-two year period 1956 to 1977. The rainfall data were provided by the South African Weather Bureau [22]. In addition to seasonality, the rainfall model developed allows for a 20 year cycle and for four shorter cycles with lengths of between 2,35 and 4,445 years.

\section{Figure 1: Monthly Rainfall for regions serving the Witwatersarand auctions}

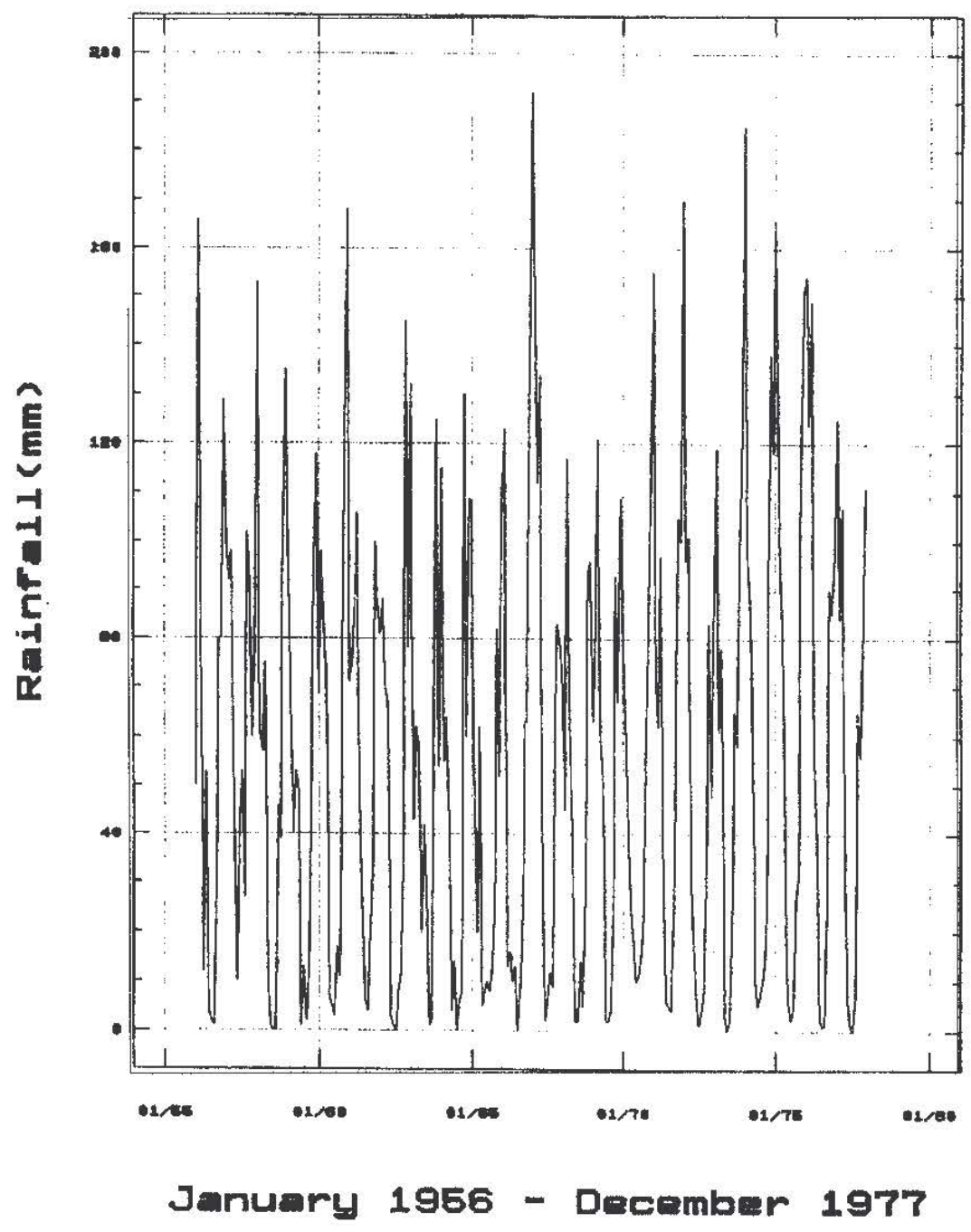

The errors for the rainfall model were uncorrelated. Following the approach of Napier-Munn, Meyer and Stratford [18] twelve independent three parameter Weibull distributions, described in the Appendix, were used to independently model the errors for each month of the year. 


\section{Beef Price Model}

The average grade beef price was modelled using the 1970-1984 boof prico data for the Witwatersrand auctions illustrated in Figure 2.

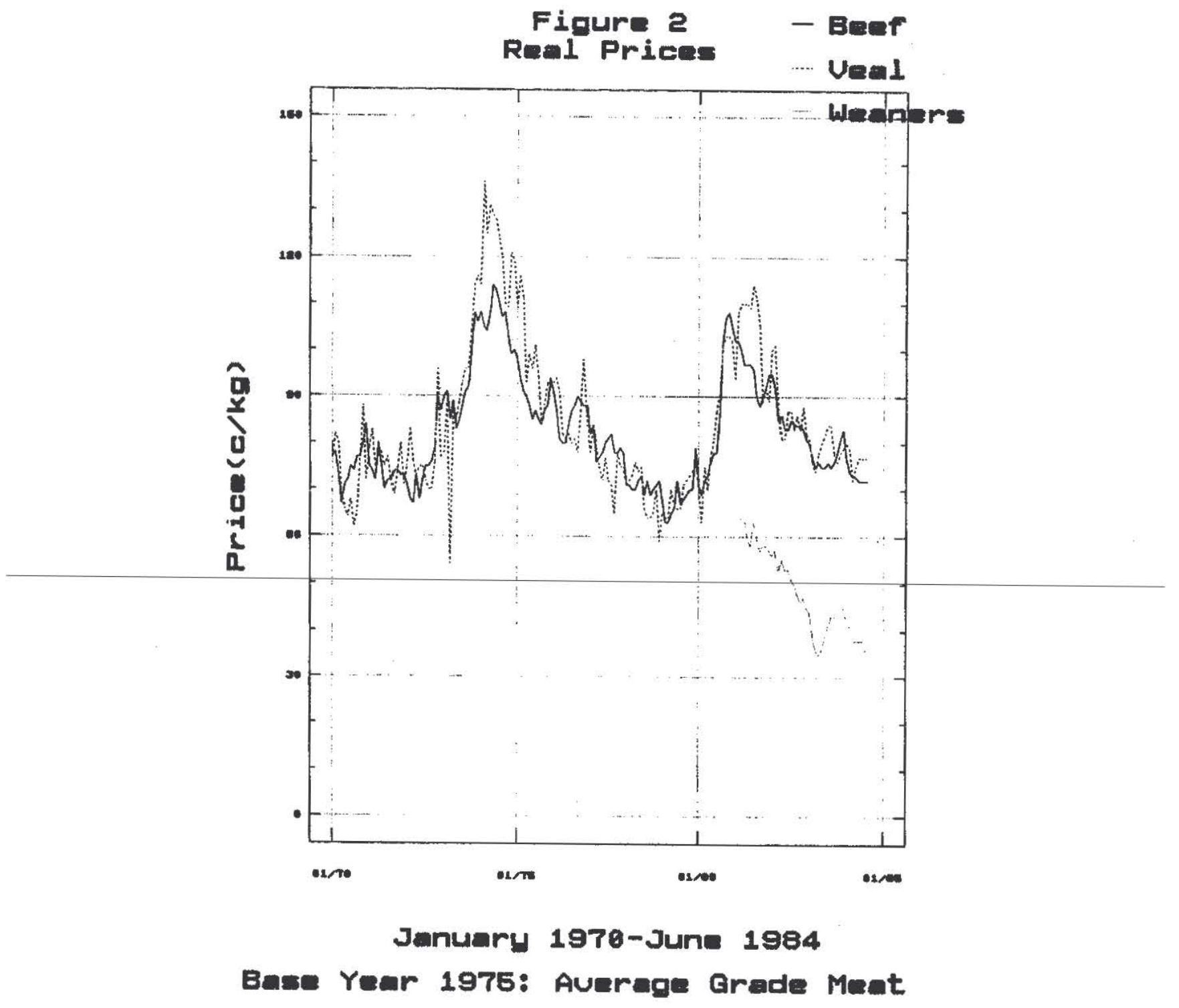

These monthly data were provided by the South African Meat Board [21]. Prices were deflated using the Consumer Price Index using 1975 as base year. The beef price model developed includes a seven year cycle and a 3,5 year cycle. The errors for this model showed non-stationarity in the form of trend and seasonality. After differencing to remove both these forms of non-stationarity the errors were found to follow a moving average one (MA(1)) normal process, as described in the Appendix. 


\section{Lick Intake Model}

The third variable which needed to be modelled was mean voluntary monthly lick intake. Data for this variable were provided by Dr. Marincowitz of the Department of Agriculture for the farm Soutpan for the period 1979-1984. The lick in question is a mineral and protein rich lick (see Marincowitz [12] for the composition of the lick). Lick intake was measured in terms of grams/LSU where LSU indicates a large stock unit. The data appear in Figure 3. Stepwise regression was used to obtain this model using rainfall and herd size (expressed in terms of LSU's) for the current and the previous few months to predict the lick intake. Multicollinearity makes nonsense of the coefficient values of this model but does not affect the predictive accuracy of the model.

Only $28 \%$ of the variability in mean monthly lick intake could be explained by this model. This is probably due to the rough method of measurement for this variable - "to the nearest half oil drum provided". The errors from this model were autocorrelated showing the form of an autoregressive one (AR(1)) normal process, as described in the Appendix.

\section{Veal and Weaner Price Models}

Next models were required for veal prices and weaner prices. The veal price model was based on data provided by the South African Meat Board [21] for the period January 1970 to June 1984, expressed in terms of 1975 rands. The weaner price model was based on data provided by Kanhym in a personal communication for the period 1981-1984. These data were also deflated using 1975 as the base year. Both series are illustrated in Figure 2. It was found that any change in the beef price caused a proportional change in the veal price and in the weaner price. For every $\mathrm{R} 1$ change in the beef price the veal price changed by $85 \mathrm{c}$ in the same direction while the weaner price changed by $40 \mathrm{c}$ in the same direction. Veal prices were also affected, to a lesser extent, by changes in the beef price 10 months previously. Changes in the beef price at this time can be expected to influence the supply of calves, and hence the supply of veal. The errors for the veal model followed a moving average one (MA(1)) process. The errors for the weaner price 


\section{4}

model were independent and could be described by a three paramotor Woibull distribution.

Figure 3: Soutpan Manthlu Date

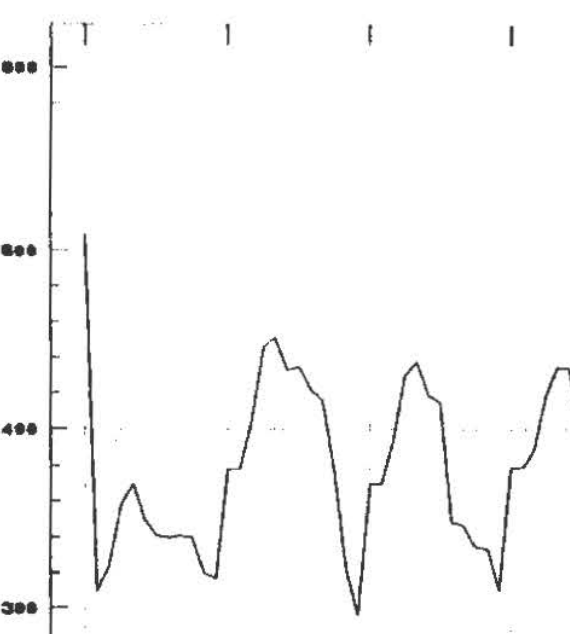

1
Lsut

Lick (gm)

Ruint (mm)
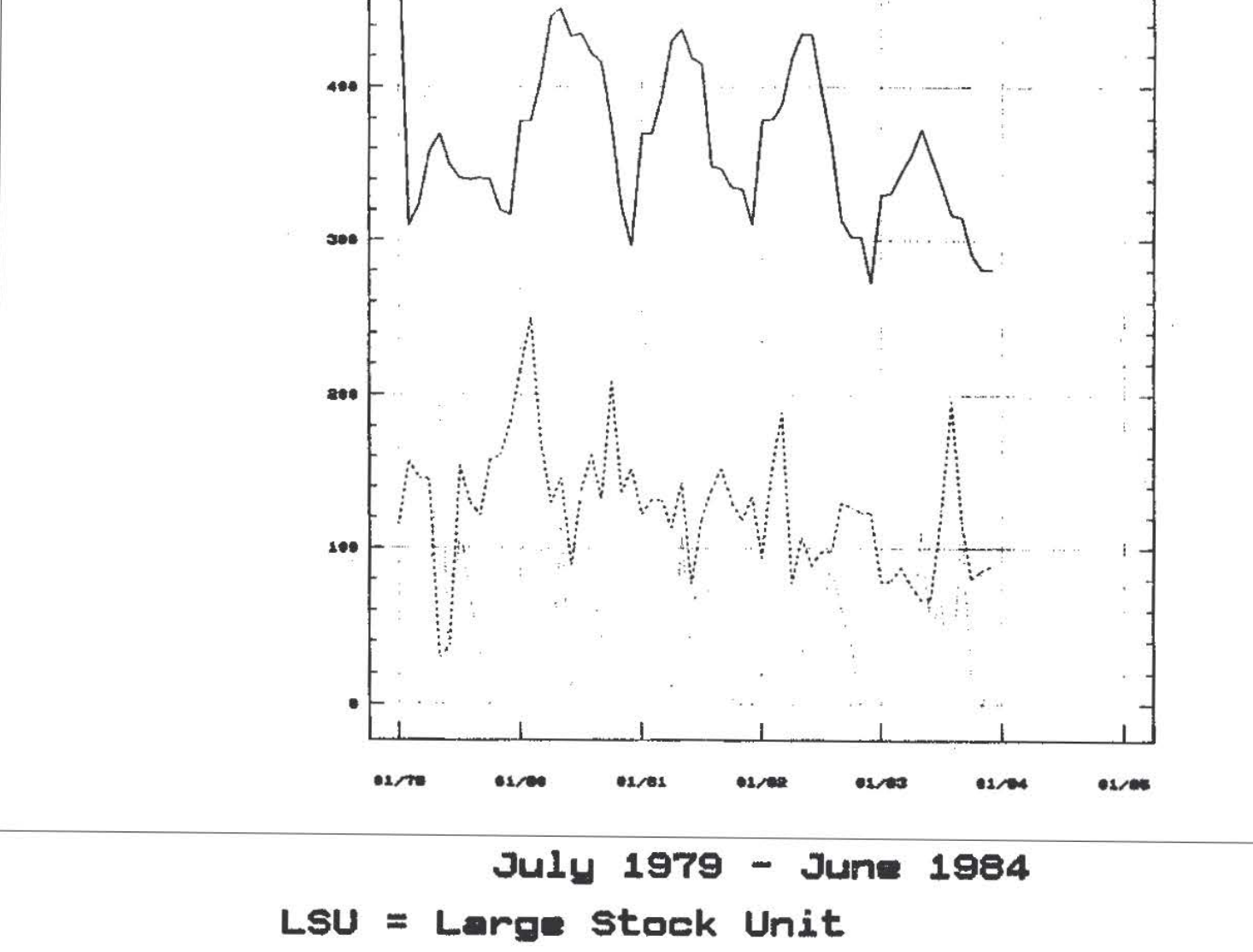

\section{Mass Gain Models}

Finally mass gain models were developed for the various age/sex categories. The mass gain models were obtained using Soutpan data, again for the period 19791984. Stepwise regression was used to model the monthly mass gain in terms of the rainfall, lick intake and herd size for the current and previous few months. Again multicollinearity makes nonsense of the coefficient values but does not affect the predictive accuracy of the model. For animals under three years of age $53-71 \%$ of the variability could be explained by these models. However, for the 
older cows this percentage fell to $34 \%$, even when an attempt was made to ignore those months when the cows calved. The effect of calving on mass gain should be addressed directly if the models for the older cows are to be improved. The data for the older cows are illustrated in Figure 4 while the data for the younger animals are illustrated in Figures 5 and 6.

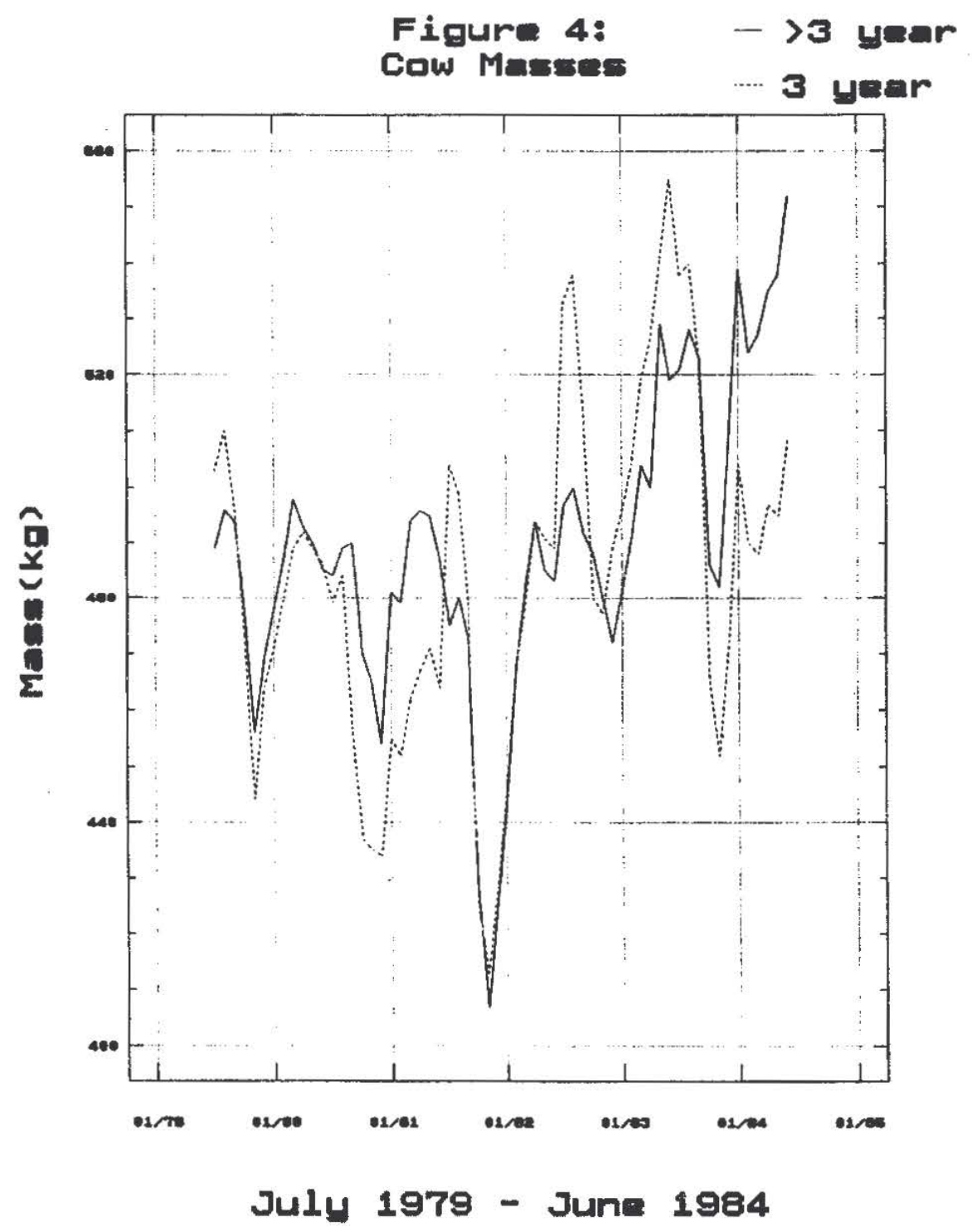

The errors for the mass gain models were independent normal for five of the six sex/age categories. Only for the 2 year old females did the errors show autocorrelation. These errors were modelled using an autoregressive one (AR(1)) process. 


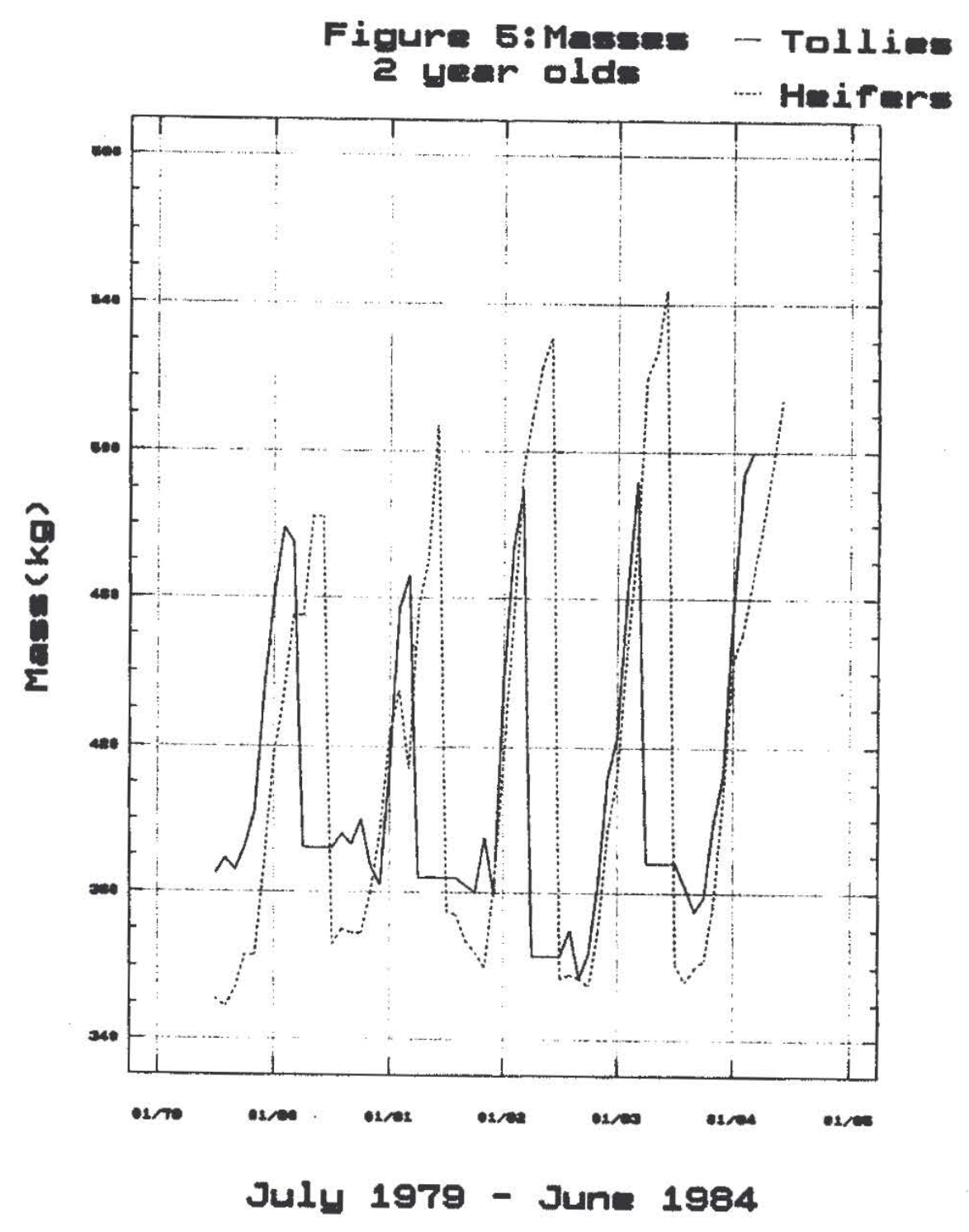

\section{Caveat}

Although these models were the best that could be found in terms of the behaviour of their residuals and in terms of the requirements of this study, it should be noted that these models are based on "old" very specific data. Consequently the above models should be regarded as examples of suitable models rather than the "best" models.

\section{DECISION-MAKING FOR THE EXTENSIVE BEEF FARMER}

The decisions considered in this study concerned the optimum choice of stocking intensity, cattle system and timing of cow sales, and the optimum degree of flexibility as regards changes in these decisions from one year to the next. The 
three cattle systems considered are briefly described in the glossary of terms. The models described in the previous section have been used to analyse these decisions. Decisions are evaluated in terms of annual gross margins (ie. revenue minus variable costs).

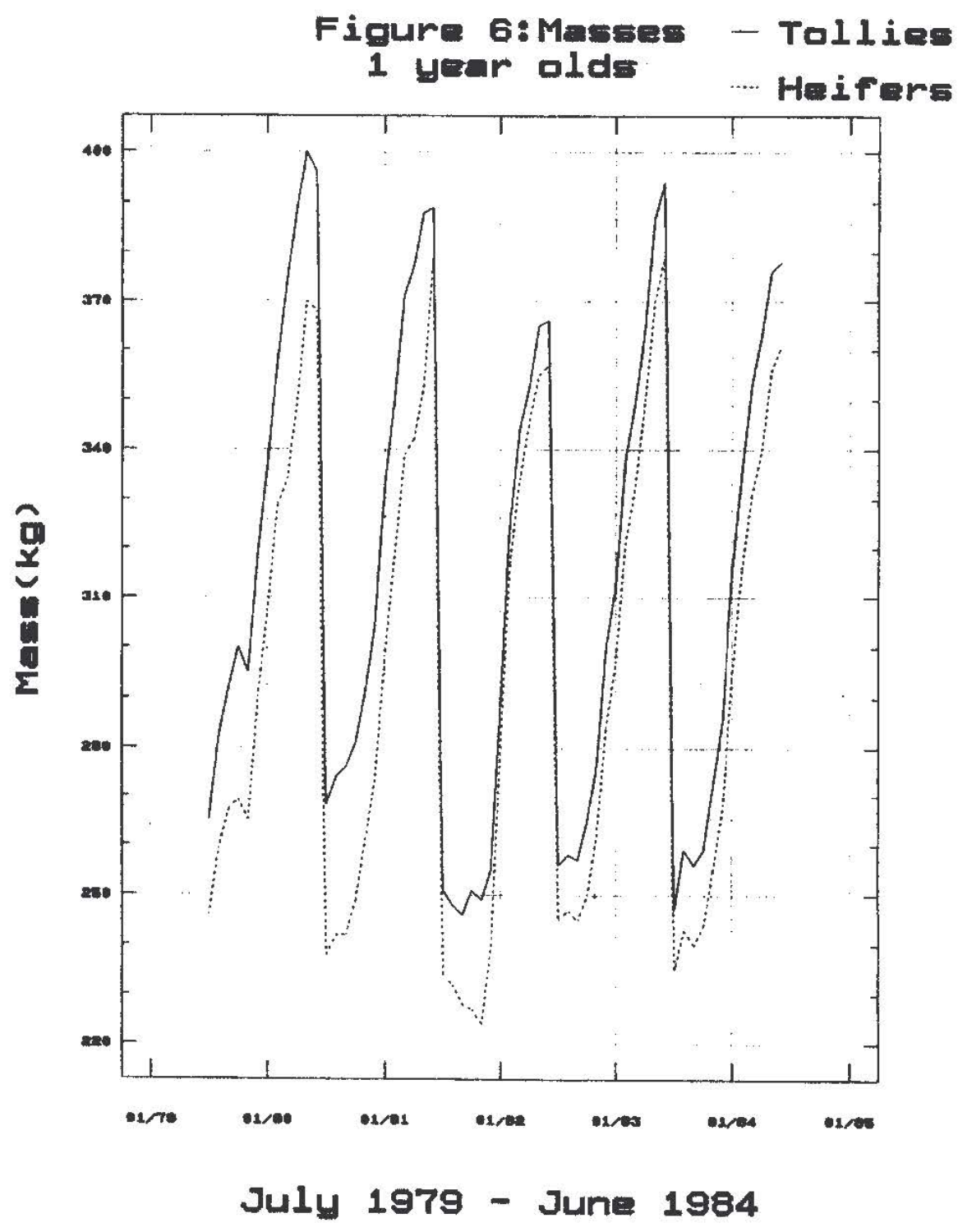

The models are based on data collected at Soutpan and the Witwatersrand auctions, consequently the conclusions are relevant only for cattle raised on the Soutpan farm and sold at the Witwatersrand auctions. No attempt has been made to test the applicability of the Soutpan mass gain and lick intake models to other farms in the region. However, it is suspected that differences in the quality of veld management may affect the reliability of these models for other farms. 
Monte Carlo simulations and Dynamic Programming are the tools used to study the consequences of the above decisions.

\section{Monte Carlo Simulation}

As shown by Clemen [2], Monte Carlo simulation is an excellent tool for capturing all the relevant aspects of uncertainty in a "messy" situation, providing the decision-maker with a sound basis for comparing alternatives. Donaldson [4] has also used this tool in an agricultural setting. He was able to compare alternative machinery systems used for cereal production using Monte Carlo simulation.

The Monte Carlo simulation used in this study consisted of 100 iterations conducted on a monthly basis over a period of 140 years. The idea in using a 140 year period was to provide a full coverage of the interaction between the 7 year beef cycle and the 20 year rainfall cycle. A more realistic period, say the next \pm 20 years, is recommended for future studies. For each iteration the error models were used to modify the expected values of the system variables as illustrated in Figure 7.

Three initial stocking intensities, three cattle systems and two different months for cow sales were compared. All three stocking intensities were typical of those seen at Soutpan in recent years. This means that the stocking intensities assumed are compatible with the lick intake and mass gain models developed using the Soutpan data. The results shown in Table 1 were obtained when cows were sold in June.

\section{Table 1}

\begin{tabular}{||l|l|l|l||}
\hline & \multicolumn{3}{|c|}{$\begin{array}{l}\text { Mean Annual Gross Margin (R100 000) with standard } \\
\text { deviations given in brackets }\end{array}$} \\
\hline & \multicolumn{3}{|c|}{ STOCKING INTENSITY } \\
\hline CATTLE SYSTEM & LOW & MEDIUM & HIGH \\
\hline TOLLIE & $15,45(2,84)$ & $18,37(3,37)$ & $21,47(3,89)$ \\
\hline WEANER & $15,26(2,71)$ & $17,98(3,25)$ & $20,84(3,79)$ \\
\hline CALF & $13,46(3,27)$ & $15,90(3,89)$ & $18,70(4,49)$ \\
\hline
\end{tabular}


Figure 7: Monthly generation of data for DSS analyses

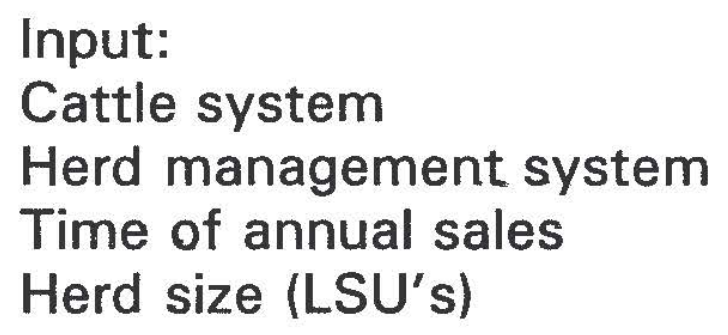

Input:

Cattle system

Herd management system

Time of annual sales

Herd size (LSU's)

- Models for expected monthly values:

Rainfall for supply region

$\Rightarrow$ Rainfall for Soutpan

$\Rightarrow$ Mass changes for each age/sex

$\Rightarrow$ Lick intake (gm/LSU/mth)

Beef price

$\Rightarrow$ Veal and weaner prices

- Error models used only for

Monte Carlo Simulation

Rainfall for supply region

Mass changes for each age/sex

Lick intake (gm/LSU/mth)

Beef price

Veal price

Weaner price

- Calculation
Annual sales
Variable costs
Gross margin

Table 1 suggests that a higher stocking intensity is desirable from the point of view of increasing gross margins. However, as indicated by Table 2, the effect of the increased stocking intensity on lick intake is large, indicating a marked decline in veld condition. In addition the standard deviations in Table 1 indicate that there is greater risk when stocking intensity is high. Clearly the tollie system is the most profitable system on average while the weaner system is the least risky. 
Table 2

\begin{tabular}{||c|c|c|c|}
\hline & \multicolumn{3}{|c|}{ Mean Annual Lick Intake (tons pa) } \\
\hline & \multicolumn{3}{|c|}{ STOCKING INTENSITY } \\
\hline & LOW & MEDIUM & HIGH \\
\hline APRIL. COW SALES & 12,2 & 15,9 & 19,9 \\
\hline JUNE COW SALES & 12,8 & 16,7 & 20,8 \\
\hline
\end{tabular}

As remarked above, the increase in lick intake between the low stocking rate (299 LSU's on 1st January) and the high stocking rate (385 LSU's on 1st January) computed in Table 2 is cause for concern. A $29 \%$ increase in herd size appears to translate into a $63 \%$ increase in lick intake. The effect of April as opposed to June cow sales is to reduce lick intake by $5-8 \%$ (while decreasing gross profits by only $\pm 2 \%$ ). This suggests that earlier sales can be used to alleviate excess pressure on the veld without causing too much of a loss in profits.

In the above analysis a stable marketing strategy (ie.cattle system) was assumed. If the farmer cannot obtain reasonably accurate predictions of future rainfall and future beef prices, this is the system one would expect him to follow. However, if he can obtain reasonably accurate predictions of future rainfall and future beef prices one would expect him to change his cattle system from time to time. The desirability of such flexibility can be assessed using dynamic programming.

\section{Dynamic Programming}

As discussed by French [6] a dynamic programming analysis works backward through a decision tree once the route with the optimum expected value has been established. One may therefore say that dynamic programming makes decisions with hindsight. Hadley [8] provides a general reference for the theory of dynamic programming. Nerlove, Grether and Carvalho [19] provide an application of dynamic programming in the context of cattle farming. They optimise the net present value of a cattle ranch in terms of sales and feeding strategies. 
In this application of dynamic programming the farmer was given the choice of changing his cattle system in any year. The goal was to maximise the present value of total gross margins allowing for all possible combinations of rainfall levels and beef price levels. It was therefore necessary to consider a period of one hundred and forty years. It is again suggested that only the next \pm 20 years be considered in future studies of this nature. Expected rainfall and beef prices were predicted from their respective models. The implications of a (possibly) changing cattle system on mass gain were predicted from the Soutpan mass-gain models and translated into gross margins using the veal, weaner and beef price models, as illustrated in Figure 7.

It was found that in certain circumstances, namely years with high rainfall, low prices and low stocking intensities it was profitable, in terms of total gross margin, for the farmer to temporarily switch from a tollie system to a weaner system. In 14 out of the 140 years the weaner system was recommended, while the calfsystem never became a viable option.

However, at higher stocking intensities it was found that the farmer should retain a tollie system throughout the 140 year period. This is actually the policy at Soutpan so it was not a surprising result. The tollie-system is apparently more resilient than the weaner or calf system to the poorer veld condition which is associated with higher stocking intensities.

\section{CONCLUSION}

This study has shown that DSS models show promise as a decision-making tool for the extensive beef farmer. If farmers are prepared to use voluntary lick intake as a measure of veld condition, DSS models can be used to simulate the effect of management decisions on gross margins and veld condition.

In this study we have considered the effect of stocking intensity, cattle system and the timing of cow sales on gross margins and veld condition. In addition it is necessary for veld condition to be calibrated, perhaps into acceptable and unacceptable ranges, using lick intake values. Once this has been done other 
decisions, such as decisions to rent extra grazing or buy in fodder, can be analysed quickly and cheaply using simulation.

This study has also shown that, if a farmer can obtain reasonably accurate forecasts of rainfall and beef prices for the next \pm 20 years, then it may be profitable for him to change these decisions from time to time. The suggestion here is that, with the help of statistical models, the farmer can become proactive rather than reactive. Based on the extra information provided by statistical models he can change his management system in order to adjust to a changed marketing and/or production environment.

However, the above suggestions are really only practical if the farmer receives some assistance. Firstly he will need model experts to help him build the models he needs. He will need computer experts to install friendly but flexible simulation and dynamic programming software on his computer. In addition he will require a marketing environment which is not a straight-jacket. He must have the freedom to sell what he wants, when he wants and in the quantities he desires. The present permit system, operated by the South African Abattoir Corporation (ABACOR) through the livestock agents, may be a problem in this regard.

\section{APPENDIX}

$A R(1)$ normal process:

A process, $x_{t}$, which can be modelled as follows:

$$
\begin{aligned}
\left(x_{t}-\mu\right) & =\phi\left(x_{t-1}-\mu\right)+\theta_{t} \\
\text { where } \mu & =E\left(x_{t}\right) \text { for all } t \\
\phi & =\text { a constant parameter } \\
\theta_{t} & \sim N\left(0, \sigma^{2}\right) \text { independently for all } t .
\end{aligned}
$$

$\mathrm{MA}(1)$ normal process:

A process, $x_{t}$, which can be modelled as follows:

$$
\begin{aligned}
\left(x_{t}-\mu\right) & =\theta_{t}-\theta \theta_{t-1} \\
\text { where } \mu & =E\left(x_{t}\right) \text { for all } t \\
\theta & =a \text { constant parameter } \\
\theta_{t} & \cdots N\left(0, \sigma^{2}\right) \text { independently for all } t .
\end{aligned}
$$


Three parameter Weibull distribution function

$$
\begin{aligned}
& F(x)=1-\exp \left(-\left(\frac{x-\beta_{0}}{\beta_{1}}\right)^{\beta_{2}}\right) \\
& \text { where } \beta_{0}, \beta_{1}, \beta_{2} \text { are constant parameters. }
\end{aligned}
$$

\section{ACKNOWLEDGEMENT}

Many thanks to the referees for their most useful comments and to all the people and institutions which so kindly assisted by providing data.

\section{REFERENCES}

[1] H.F.BREIMYER, Observations on the cattle cycle. Agricultural Economic Research, 7, 1-11 (1955).

[2] R.T.CLEMEN, Making hard decisions: An introduction to decision analysis. PWS-KENT Publishing Co. Boston (1991).

[3] R.P.DENNY, Drought and the veld. Zimbabwe Agricultural Journal, 80(5), 169-174 (1983).

[4] G.F.DONALDSON, The study of agricultural systems: Application to farm operations. Study of agricultural systems. Editor G.E.Dalton, 267-306. Applied Science Publishers Ltd.London (1975).

[5] T.G.J.DYER, Secular variation in South African rainfall. Ph.D. University of the Witwatersrand (1975).

[6] S.FRENCH, Readings in decision analysis. Chapman and Hall, New York (1989).

[7] D.M.GAMMON, Veld management, stocking rate and drought considerations. Zimbabwe Agricultural Journal, 80(5), 183-185 (1983).

[8] G.HADLEY, Nonlinear and dynamic programming. Addison-Wesley Publishing Company, Reading, Mass. (1970).

[9] I.T.HAWRYSZKIEWYCZ, Introduction to system analysis and design. Prentice Hall, Sydney (1991).

[10] J.F.IKERD and K.B.ANDERSON, Risk rated management strategies for farmers and ranchers. OSU Extension Facts, 159, Oklahoma University (1983). 
[11] P.G.W.KEEN and M.S.SCOTT MORTON, Decision support systems: An organizational perspective. Addison-Wesley Publishing Company, Reading, Mass. (1978).

[12] G.MARINCOWITZ, Vrugbaarheid van vleisbeeste op die Soutpan beesplaas. Suid Afrikaanse Tydskrif Veekunde, 8, 119-123 (1978).

[13] G.MARINCOWITZ and J.G.LOW, Extensive cattle ranching at Soutpan. Farming in South Africa, D.1.7, 1-4 (1979).

[14] G.MARINCOWITZ, Kuddebestuur en kuddeprestasie op Soutpan oor tyd. Agrivaal, 4, 12, 9-20 (1982).

[15] D.L.MEADOWS, Dynamics of Commodity Production Cycles. Wright-Allen Press Inc., Cambridge, Mass. (1970).

[16] D.H.MEYER, Production planning for extensive beef farmers in South Africa. DBL University of South Africa (1986).

[17] D.H.MEYER, Does drought really depress beef prices in South Africa? Studies in Economics and Econometrics, 12(2), 7-14 (1988).

[18] T.J.NAPIER-MUNN, D.H.MEYER and K.J.STRATFORD, The Monte Carlo simulation of correlated monthly rainfall and evaporation data. South African Geographical Journal, 60(1), 41-62 (1978).

[19] M.NERLOVE, D.M.GRETHER and J.L.CARVALHO, Analysis of economic time series: A synthesis. Academic Press Inc. London Ltd. (1979).

[20] F.D.RICHARDSON, Short and long-term influences of undernutrition on range cattle production. Zimbabwe Agricultural Journal, 80(5), 175-182 (1983).

[21] South African Meat Board. Annual Reports, 1978-1983.

[22] South African Weather Bureau. Climate of South Africa Part 10: District Rainfall for South Africa and the March of Rainfall over South Africa, WB35 (1972).

[23] R.H.WESTFALL, N.VAN ROOYEN and G.K.THERON. Veld condition assessments in sour bushveld. Proceedings Grass/and Society of South Africa, 18, 72-80 (1983).

[24] W.F.WILLIAMS and T.T.STOUT. Economics of the Livestock Meat Industry, Macmillan, New York (1964). 